\title{
Extração e fracionamento simultâneo do óleo da castanha-do-Brasil com etanol
} Extraction and simultaneous separation of the Brazil nuts oil with ethanol

\author{
Suely Pereira FREITAS ${ }^{1 *}$, Otniel FREITAS-SILVA², Iara Conceição de MIRANDA ${ }^{1}$, Maria Alice Zarur COELHO ${ }^{1}$
}

\section{Resumo}

O objetivo deste trabalho foi utilizar o etanol comercial para extração e fracionamento simultâneos das frações lipídicas presentes na castanha-do-Brasil (Bertholletia excelsea H.B.K.). O óleo foi obtido a partir da castanha desidratada e moída. O processo foi conduzido na proporção $4: 1$ solvente/substrato (v.p ${ }^{-1}$ ) em banho termostatizado a $65{ }^{\circ} \mathrm{C}$, sob agitação de $30 \mathrm{rpm}$. A mistura foi filtrada, resfriada a $10{ }^{\circ} \mathrm{C}$ e, a seguir, centrifugada para separação das fases: uma fase com consistência de gel (micela rica), contendo $75 \%$ de óleo e $25 \%$ de etanol, e a outra líquida, contendo $2,4 \%$ de óleo e $97,6 \%$ de etanol (micela pobre). Pelas características apresentadas, a micela rica tem potencial para ser utilizada no preparo de cremes vegetais como substituto parcial de gorduras hidrogenadas, cujos efeitos biológicos na saúde dos consumidores vêm provocando muitas polêmicas. Além de ser uma alternativa na obtenção de gorduras para a formulação de alimentos mais seguros, a tecnologia proposta poderá ser estendida a diferentes oleaginosas de interesse comercial, eliminando o uso de n-hexano no processamento de óleos e gorduras vegetais.

Palavras-chave: gorduras vegetais; ácidos graxos; solubilidade; etanol.

\begin{abstract}
In this work, the extraction and simultaneous separation of lipids from Brazil nuts (Bertholletia excelsa H.B.K.) with ethanol were investigated. Brazil nuts were dried and triturated prior to oil extraction. The process was carried out at a rate of 4:1 solvent to substrate (v.w ${ }^{-1}$ ). The raw material and ethanol were placed in an erlenmeyer flask and maintained in a temperature-controlled bath at $65^{\circ} \mathrm{C}$ and $30 \mathrm{rpm}$. After $1 \mathrm{hour}$, the mixture was filtered under a vacuum and the resultant miscella was maintained at $10{ }^{\circ} \mathrm{C}$ and centrifuged for phase separation. A rich miscella containing $75 \%$ oil and $25 \%$ ethanol was obtained presenting a gel consistency while a poor miscella, containing $2.4 \%$ oil and $97.6 \%$ ethanol, was liquid. The rich miscella presented an important potential to partially replace hydrogenate fats in the food industry. Scientific studies indicated that the consumption of trans fatty acids promote serious health effects. Furthermore, the proposed technology can be extended to different commercial oleaginous by eliminating the use of n-hexane in vegetable oils extraction.

Keywords: vegetable fats; fatty acids; solubility; ethanol.
\end{abstract}

\section{Introdução}

Os séculos XIX e XX foram marcados pelo consumo de alimentos processados, criando um modelo de transformação que se baseia na oferta de produtos padronizados para o mercado de massa e em tecnologias que aumentam a produtividade e reduzem os custos de produção. O cenário atual exige maior compromisso com o meio ambiente e com a qualidade dos produtos acabados.

A industrialização de oleaginosas constitui-se em uma das mais importantes atividades do agronegócio Brasileiro pela utilização dos seus produtos na formulação de alimentos, de cosméticos e de fármacos. Recentemente, o uso de óleos vegetais para fins energéticos tem ampliado o interesse do governo, de empresas privadas e das instituições de pesquisa tanto no aperfeiçoamento dos processos de extração de óleos quanto na busca de fontes alternativas deste produto ${ }^{7}$.

O processo convencional de obtenção de óleos vegetais é realizado por prensagem da matéria-prima seguida da extração com n-hexano. Este solvente é inflamável e mais denso que o ar, colocando em risco empregados e comunidades próximas

\footnotetext{
Departamento de Engenharia Química, Escola de Química

Universidade Federal do Rio de Janeiro - UFRJ, Centro de Tecnologia, Bloco E, sala 207, CEP 21949-900, Ilha do Fundão, Cidade Universitária,

Rio de Janeiro - RJ, Brasil,

E-mail:freitasp@eq.ufrj.br

Embrapa Agroindústria de Alimentos, Av. das Américas, 29501, Guaratiba,

CEP 23020-470, Rio de Janeiro - RJ, Brasil,

E-mail: ofreitas@ctaa.embrapa.br

* A quem a correspondencia deve ser enviada
}

à fábrica. Para cada tonelada de grão processado, cerca de $2 \mathrm{~L}$ de solvente são perdidos para o meio ambiente. Por esta razão, o processo de extração de óleos vegetais é considerado pelos órgãos de proteção ambiental como um dos maiores responsáveis pela emissão de gases do efeito estufa ${ }^{9}$.

O objetivo deste trabalho foi utilizar o etanol para extração e fracionamento das frações lipídicas presentes na castanhado-Brasil.

A obtenção de etanol a partir da cana de açúcar coloca o Brasil em uma posição privilegiada na eliminação do uso de derivados de petróleo no processamento de oleaginosas. O etanol, além de ser obtido de fontes renováveis, não é tóxico e independe do mercado internacional do petróleo ${ }^{3}$.

O fruto da castanheira, comumente chamado ouriço, possui uma casca lenhosa e bastante dura, pode conter de 15 a 24 sementes, cujo tamanho varia entre 4 e 7 centímetros de comprimento (Figura 1). Essas sementes também têm uma casca bastante dura e rugosa e contêm uma amêndoa muito apreciada ${ }^{10}$. A maior parte da castanha-do-Brasil destina-se ao consumo in natura. Entretanto, a castanha-do-Brasil possui uma ampla cadeia de produtos e subprodutos, sendo recomendada como matéria-prima para extração de óleo, devido ao elevado conteúdo de lipídios. A amêndoa da castanha-doBrasil é constituída de 60 a $70 \%$ de lipídios e de 15 a 20\% de proteína, além de vitaminas e minerais. O óleo típico apresenta 13,8\% de ácido palmítico, 8,7\% de ácido esteárico, 31,4\% de ácido oléico e $45,2 \%$ de ácido linoléico, além de pequenas quantidades dos ácidos mirístico e palmitoléico. O óleo da 
castanha-do-Brasil tem sido utilizado como óleo fino de mesa e na formulação de cosméticos ${ }^{5}$.

A tecnologia proposta poderá ser estendida a diferentes oleaginosas de interesse comercial eliminando, no futuro, o uso de n-hexano neste setor da agroindústria nacional, além de ser uma alternativa na obtenção de gorduras para a formulação de alimentos mais seguros.

\section{Material e métodos}

\subsection{Matéria-prima}

A castanha-do-Brasil (Bertholletia excelsea H.B.K.) foi fornecida in natura pela Embrapa Agroindústria de Alimentos e é nativa do Estado do Acre. Para reduzir o crescimento de fungos, comumente presentes nas amêndoas, a matéria-prima foi autoclavada sob pressão de $1 \mathrm{~atm}\left(100{ }^{\circ} \mathrm{C}\right)$, resfriada, embalada em sacos plásticos e armazenada em local escuro e livre de umidade, entre 20 e $22{ }^{\circ} \mathrm{C}$. As castanhas foram posteriormente quebradas com o auxílio de um quebrador de nozes (Figura 1).

\subsection{Extração}

O óleo foi obtido a partir da castanha moída ( $1 \mathrm{~mm}<$ dp $<3 \mathrm{~mm}$ ). O processo foi conduzido na proporção $4: 1$ solvente/substrato (v. $\mathrm{p}^{-1}$ ) em banho termostatizado a $65{ }^{\circ} \mathrm{C}$, sob agitação de $30 \mathrm{rpm}$. A mistura foi filtrada a vácuo de modo a separar a micela (mistura de etanol e óleo) da torta desengordurada. A micela foi resfriada a $10{ }^{\circ} \mathrm{C}$ e, a seguir, centrifugada para separação das fases em duas condições: a $20{ }^{\circ} \mathrm{C}$ e na temperatura ambiente $\left( \pm 30^{\circ} \mathrm{C}\right.$ ). O precipitado (com baixo teor de etanol) foi seco com fluxo de ar frio, enquanto o sobrenadante (com elevado teor de etanol) foi processado em rotaevaporador sob vácuo a $55{ }^{\circ} \mathrm{C}$, para separação da fração solúvel. Todas as frações e produtos obtidos foram pesados em balança analítica com precisão de 0,001 g para elaboração do balanço de massa.

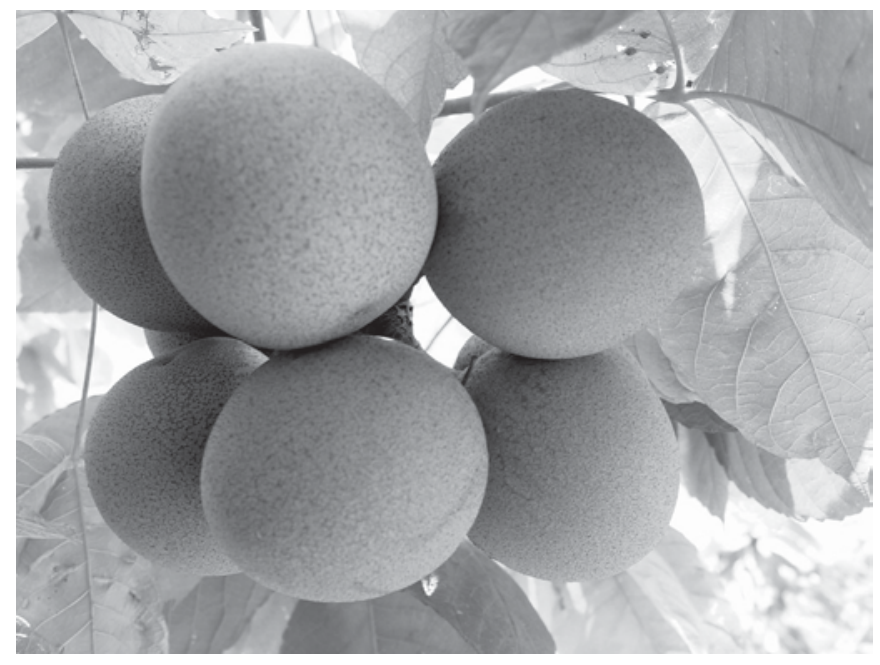

Figura 1 - Fotos do ouriço e da castanha-do-Brasil.

\subsection{Análises}

O teor de óleo foi determinado em aparelho soxhlet sob refluxo com éter de petróleo a $50{ }^{\circ} \mathrm{C}$ por 12 horas $^{1}$. O índice de peróxidos foi realizado de acordo com o método oficial da AOCS Cd $853^{2}$. A análise de acidez foi realizada segundo o método AOCS Ca $5 \mathrm{a} 40^{2}$ e expresso em p.p ${ }^{-1}$ de ácido oléico. A composição em ácidos graxos foi determinada por cromatografia. Nesta análise, os ésteres metílicos foram preparados de acordo com a metodologia de HARTMAN e LAGO ${ }^{6}$ e analisados em cromatógrafo a gás Varian $G C$ equipado com detector de ionização de chama. Para este fim, utilizou-se uma coluna de sílica fundida Omegawax 250 (30 m x 0,25 mm x 0,25 $\mu \mathrm{m}$ ). A temperatura inicial da coluna foi de $50{ }^{\circ} \mathrm{C}$, e a temperatura final de $220^{\circ} \mathrm{C}$, com programação de $4{ }^{\circ} \mathrm{C} / \mathrm{min}$; as temperaturas do injetor e do detector foram $250^{\circ} \mathrm{C} \mathrm{e} 280^{\circ} \mathrm{C}$, respectivamente, e o fluxo de hidrogênio foi de $5 \mathrm{~mL} \cdot \mathrm{min}^{-1}$. A diluição da amostra foi de $1 \%$ e o volume injetado variou de 1 a $2 \mu$ l. Estes ésteres foram identificados por comparação com os tempos de retenção dos padrões.

\section{Resultados e discussão}

O teor médio de óleo obtido na amostra, em base seca, foi cerca de 65\%. Este valor é compatível com resultados reportados por GUTIERREZ, REGITANO-D'ARCE e RAUEN-MIGUEL ${ }^{5}$, entre 60 e 70\%. O índice de peróxido do óleo variou entre 0 e 0,273 meq. $\mathrm{kg}^{-1}$ e o teor de acidez entre 0,55 e 0,56 expresso em percentagem de ácido oléico, indicando que a qualidade do óleo da castanha foi preservada apesar da amostra in natura apresentar contaminação por fungos.

O precipitado apresentou consistência de gel contendo, em média, $75 \%$ de óleo e $25 \%$ de etanol (micela rica) e a fase sobrenadante, consistência líquida contendo, em média, 2,4\% de óleo e 97,6\% de etanol (micela pobre). Como esperado, a maior parte do óleo ficou retida na micela rica com coeficiente de distribuição variando entre 4,4 e 4,7 (óleo precipitado/óleo solúvel) a $20{ }^{\circ} \mathrm{C}$ (Figura 2). O balanço de massa do processo está apresentado no fluxograma da Figura 3.

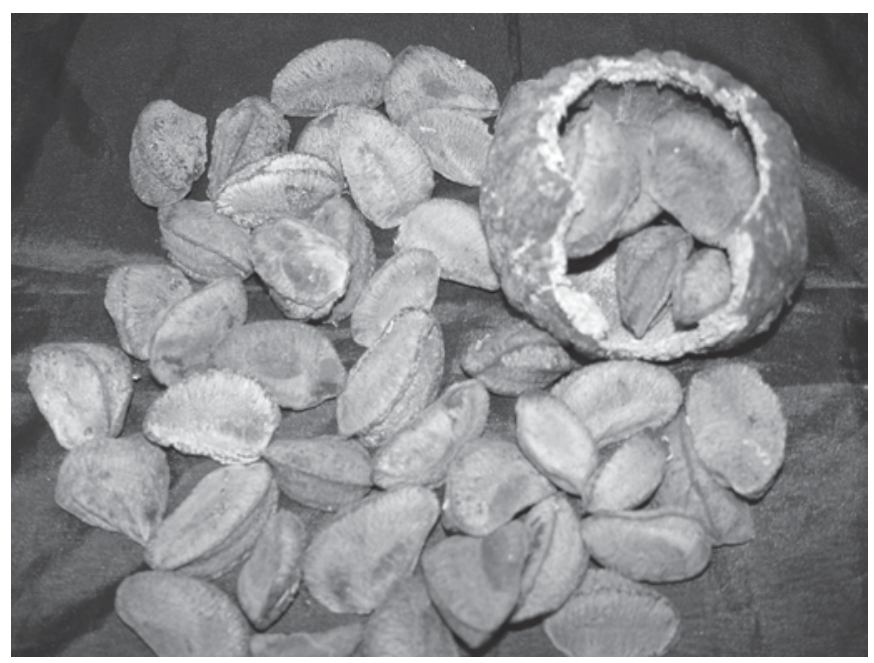




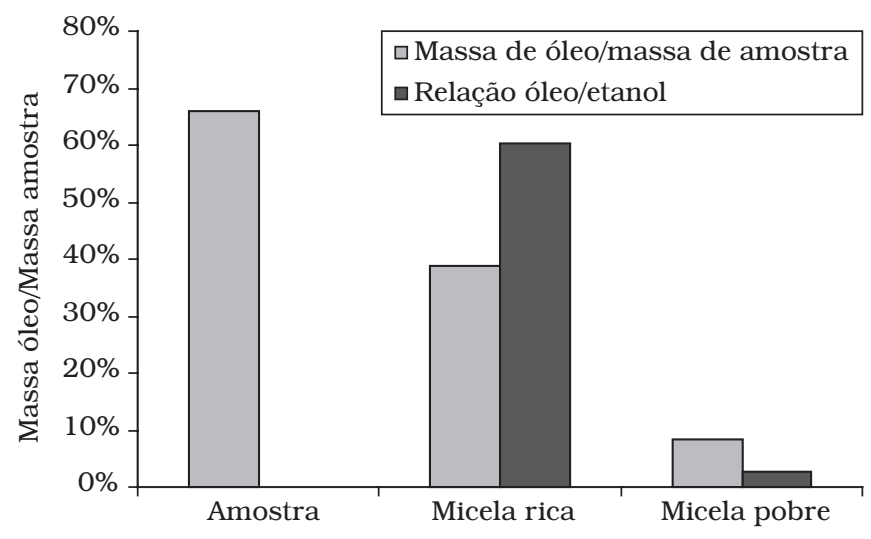

Figura 2. Rendimento do processo e teor de óleo nas frações obtidas.
O rendimento de extração, expresso pela razão entre o óleo recuperado e o óleo na amostra, foi cerca de $75 \%$, inferior a valores obtidos com n-hexano (99\%). Isto ocorre devido ao elevado teor de óleo na castanha e à baixa solubilidade dos óleos em etanol na temperatura de $65{ }^{\circ} \mathrm{C}$. Este resultado pode ser melhorado avaliando-se o impacto dos principais parâmetros do processo: temperatura e umidade da mistura. A presença de água na amostra e no solvente reduz sensivelmente a solubilidade do óleo em etanol ${ }^{4,8}$.

Pode-se observar, a partir das análises de ácidos graxos das amostras centrifugadas a $20{ }^{\circ} \mathrm{C}$, que na micela rica os ácidos graxos de alto ponto de fusão mirístico $\left(\mathrm{PF}=54,4^{\circ} \mathrm{C}\right)$, palmítico $\left(\mathrm{PF}=63,1^{\circ} \mathrm{C}\right)$ e esteárico $\left(\mathrm{PF}=69,6{ }^{\circ} \mathrm{C}\right)$ estão em maior proporção que na micela pobre, na qual predominam os ácidos graxos insaturados com menor ponto de fusão: oléico

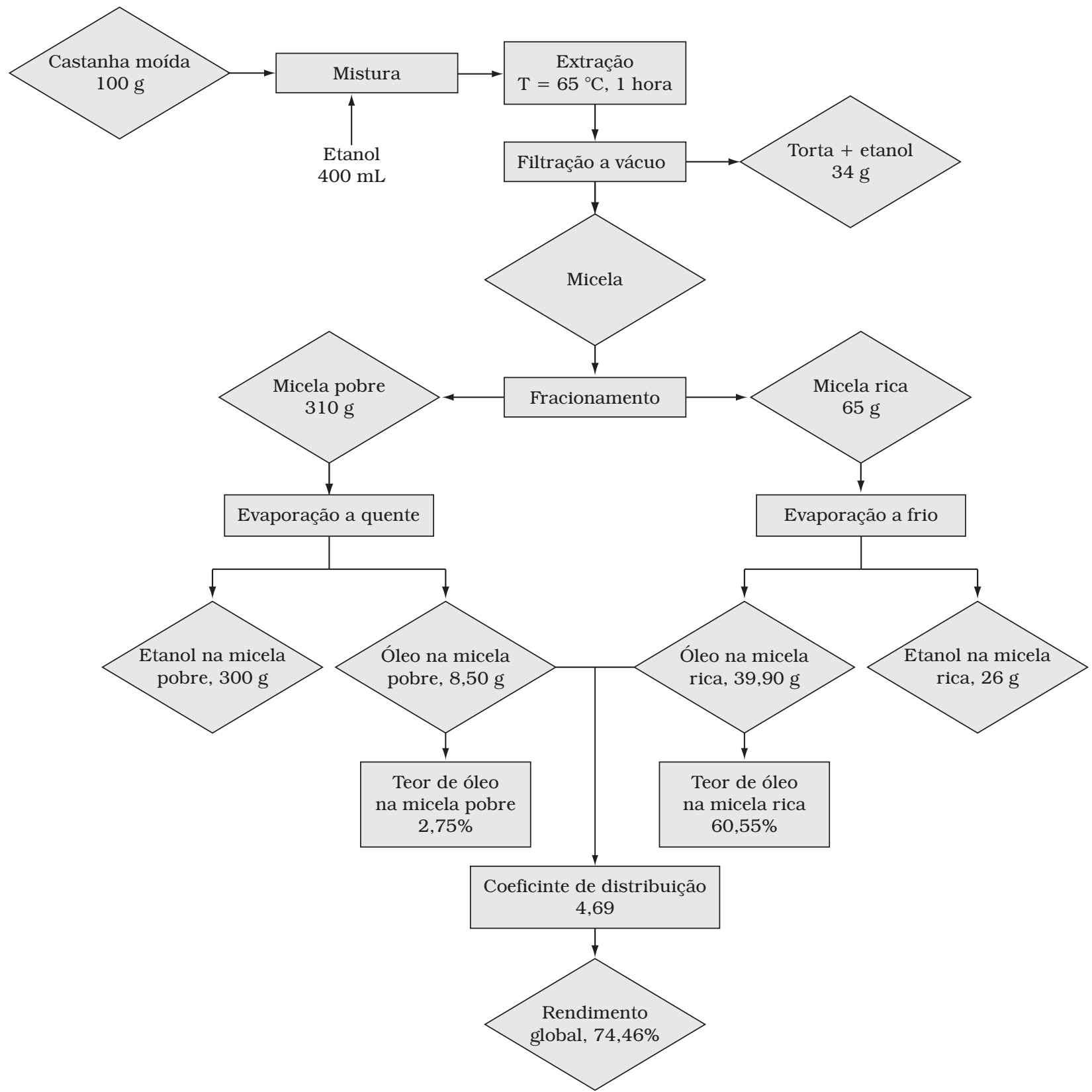

Figura 3. Fluxograma e balanço de massa do processo de extração e fracionamento a $20^{\circ} \mathrm{C}$ do óleo de castanha-do-Brasil. 
Tabela 1. Composição em ácidos graxos das frações lipídicas obtidas, a partir da castanha-do-Brasil, com etanol.

\begin{tabular}{|c|c|c|c|c|}
\hline \multirow[t]{2}{*}{ Ácidos graxos } & \multicolumn{2}{|c|}{ Separação a $20^{\circ} \mathrm{C}$} & \multicolumn{2}{|c|}{ Separação a $30^{\circ} \mathrm{C}$} \\
\hline & Micela rica & Micela pobre & Micela rica & Micela pobre \\
\hline C16:1 & 0,24 & 0,39 & 0,25 & 0,28 \\
\hline C18:1 & 26,98 & 33,46 & 29,26 & 26,63 \\
\hline C18:2 & 45,01 & 50,28 & 44,51 & 46,84 \\
\hline Total insaturados & 72,23 & 84,14 & 74,02 & 73,75 \\
\hline $\mathrm{C} 14: 0$ & 0,15 & 0,07 & 0,08 & 0,19 \\
\hline C16:0 & 16,38 & 10,66 & 14,86 & 15,80 \\
\hline $\mathrm{C} 17: 0$ & 0,09 & 0,06 & 0,08 & 0,09 \\
\hline C18:0 & 10,84 & 4,77 & 10,65 & 8,85 \\
\hline C20:0 & 0,29 & 0,24 & 0,31 & 0,25 \\
\hline Total saturados & 27,75 & 15,80 & 25,98 & 25,18 \\
\hline $\mathrm{ni}^{*}$ & 0,02 & 0,06 & 0,00 & 1,07 \\
\hline Relação insaturados/saturados & 2,60 & 5,32 & 2,85 & 2,93 \\
\hline
\end{tabular}

*ni - não identificados.

$\left(\mathrm{PF}=16{ }^{\circ} \mathrm{C}\right)$ e linoléico $\left(\mathrm{PF}=-5^{\circ} \mathrm{C}\right)$. $\mathrm{O}$ mesmo fato não foi observado nas amostras centrifugadas a $30{ }^{\circ} \mathrm{C}$. Neste caso, as duas frações apresentaram diferenças pouco relevantes na distribuição dos ácidos graxos (Tabela 1).

\section{Conclusões}

Pelas características físico-químicas, o gel obtido (micela rica) tem potencial para ser utilizado no preparo de cremes vegetais como substituto parcial de gorduras hidrogenadas bem como na elaboração de cosméticos. O óleo da fase líquida (micela pobre) é rico em ácidos graxos insaturados e é recomendado para consumo como óleo comestível ou na elaboração de produtos fitoterápicos.

A proporção entre os ácidos graxos saturados e insaturados pode ser controlada durante o fracionamento, alterando-se a temperatura de centrifugação da micela.

A tecnologia proposta elimina o uso do n-hexano na extração de óleos vegetais, além de ser uma alternativa na obtenção de gorduras vegetais para a formulação de alimentos mais seguros.

O processo deve ser aperfeiçoado antes de sua implementação em escala industrial. A extração pode ser realizada em múltiplos estágios, reciclando a micela pobre, para que se possa alcançar um rendimento compatível com o processo convencional.

\section{Agradecimentos}

Os autores agradecem à FAPERJ e ao CNPq pelo apoio financeiro.

\section{Referências bibliográficas}

1. AOAC. International official methods of analyses 17 th ed. Washington D.C., 2000.

2. AOCS - AMERICAN OIL CHEMISTS' SOCIETY. Official methods and recommended practices of the american oil chemists' society, Champaign, IL., 2004.

3. CARVALHO, L. C. C. Álcool do Brasil: energia limpa e renovável. Agroanalysis, São Paulo, FGV, v. 21, n. 9, set, 2001.

4. FREITAS, S. P.; FREITAS-SILVA, O.; RODRIGUES, V. S.; VIEIRA, T. M. F. S.; TASSINARI, P. Extração de cafés com etanol comercial: avaliação da composição em ácidos graxos. In: Seminário Latino Americano Y Del Caribe de Ciência e Tecnologia de Alimentos, $13^{\circ}, 12$ a 16 de outubro de 2004, MontevidéuUruguai.

5. GUTIERREZ, E. M. R.; REGITANO-D ARCE, M. A. B.; RAUENMIGUEL, A. M. O. Estabilidade oxidativa do óleo bruto da castanha do Pará (Berthollethia excelsa). Ciência e Tecnologia Alimentos, Campinas, v. 17, n. 1, p. 22-27, 1997.

6. HARTMAN, L.; LAGO, R. C. A. Rapid preparation of fatty acid methyl esters from lipids. Laboratory Practice, Londres, v. 22 , p. 475-477, 1973.

7. LAGO, R. C. A.; FREITAS, S. P. Extração dos óleos de café verde e da borra de café com etanol comercial. Comunicado Técnico $\mathrm{n}^{\circ}$. 92, Embrapa, dezembro de 2006. ISBN: 01035231.

8. RITTNER, H. Extraction of vegetable oils with ethyl alcohol. In: International Meeting on Fats and Oils. 1991, Technology, Proceedings, Campinas-SP GTZ, p. 17-30.

9. SCHWARZBACH, J. Aspectos de segurança relacionados ao hexano na extração de óleos vegetais. Óleos e Grãos, São Paulo, Ed. Aspen, mar-abr. p. 27-34, 1997.

10. VILHENA, M. R. Ciência, tecnologia e desenvolvimento na economia da castanha-do-Brasil: a transformação Industrial da castanha-do-Brasil na COMARU - Região Sul do Amapá. Campinas - SP, 2004, 120 p. Dissertação (Mestre em Tecnologia de Alimentos), Faculdade de Engenharia de Alimentos, Universidade Estadual de Campinas (UNICAMP). 